\title{
The electrocardiogram of athletes Comparison with untrained subjects ${ }^{2}$
}

\author{
W. Van Ganse, L. Versee, W. Eylenbosch and K. Vuylsteek \\ From Laboratorium voor Gezondheidsleer en Sociale Geneeskunde, \\ Faculty of Medicine, Ghent University, Belgium
}

The resting electrocardiograms of 30 cyclists currently involved in competitive sport were compared with those of an equal number of healthy controls matched for age, height, and weight. The cyclists had significantly lower heart rates, longer $P Q, Q R S$, and $Q T c$ intervals, higher $T$ waves in lead II, left axis deviation of the $T$ wave, higher $R$ waves in the right and deeper $S$ waves in the left praecordial leads, and deeper $S$ waves in the right and higher $R$ waves in the left praecordial leads.

No significant differences were found in the incidence of incomplete right bundle-branch block, or in the mean $Q R S$ axis, algebraic sum of $Q, R$, and $S$ in the standard leads, algebraic sum of the $T$ waves in the standard leads, and the height of the praecordial $T$ waves.

No correlation was found between incomplete right bundle-branch block and other electrocardiographic findings suggestive of right ventricular hypertrophy.

The possible significance of these findings should be assessed by prolonged prospective studies in athletes and untrained control subjects.

Apart from their importance in assessing the role and the importance of various aetiological factors, epidemiological investigations of coronary heart disease have repeatedly stressed the need for careful standardization of study methods (Blackburn, 1965). For example, Simonson's excellent study (196r) clearly shows that one has to rely on stringent criteria of selection and measurement in order to be sure whether the electrocardiogram is normal or not.

To our knowledge, such criteria have not been applied to trained athletes, a group in which electrocardiographic 'abnormalities' are currently judged to be frequent. Most studies of the electrocardiogram of athletes are either isolated case reports, for example Wenckebach heart block (Cullen and Collin, 1964), or uncontrolled group studies. The criteria for normality in the latter depend on the experience of the investigator or, more frequently, are based on dubious normal values obtained in groups of uncertain composition. A possible exception is Beckner and Winsor's study (1954) in which the electrocardiograms of 165 Marathon runners were

\footnotetext{
Received 12 December 1968.

1 Presented in part at the Vth International Congress of Hygiene and Preventive Medicine, Rome, 8-12 Oct 1968. This study was assisted in part by a grant of the National Fonds voor Wetenschappelijk onderzoek, Brussels, Belgium.
}

compared with those of 40 non-runners. However, their controls were not matched for age or body build, both of which are known to influence, among other parameters, the electrical QRS axis (Kilty and Lepeschkin, 1965) and the amplitude of the QRST deflections (Manning and Smiley, 1964). Furthermore, the fact that the controls were active aeroplane pilots casts some doubt on the representative value of this group for the non-trained general population.

This paper attempts to find out whether the electrocardiogram of athletes is characterized by any specific features which cannot be ascribed to age or to general body build. To some extent, it also investigates the significance of any changes in relation to the degree of physical training.

\section{Subjects and methods}

Only professional or semi-professional cyclists were studied. They had all been active in competitive sport for at least two years and were examined after they had been taking part for at least two months in the current season's competitions. The cardiorespiratory state was assessed by clinical examination, fluoroscopy, simple ventilatory function tests (vital capacity and $\mathrm{FEV}_{1.0}$ ), and routine blood and urine tests. The control subjects were chosen from the male participants in an epidemiological survey carried out by this laboratory in a rural population near Ghent. Subjects who had been involved in competitive sport 
were excluded, as were those whose clinical, biochemical, or lung function findings might have affected the electrocardiogram. The controls were matched with the study subjects according to the following criteria: age \pm 2 years, weight $\pm 5 \mathrm{~kg}$., height $\pm 5 \mathrm{~cm}$.

The electrocardiograms ( 12 leads) were recorded in the recumbent position at a speed of 25 $\mathrm{mm}$./min. by the same technician. Care was taken to ensure consistency in positioning of the praecordial electrodes. Tracings judged technically unsatisfactory by the criteria of the American Heart Association (1954) were rejected. Included in this study were 30 athletes and 30 controls.

At least three cardiac cycles were analysed in each lead. The amplitude of the deflections was measured in millimetres and the duration in centiseconds. The following items were studied: heart rate, calculated as the mean of the rates in $V_{2}, V_{4}$, V6; mean QRS axis of the three standard leads; mean $T$ axis of the three standard leads; PQ interval in lead II; QRS interval taken as the widest of the three standard leads; QTc calculated as the average value of $\mathrm{QT}$ in $\mathrm{V}_{2}, \mathrm{~V}_{4}$, and V6 and corrected for heart rate (Bazett's formula); the algebraic sum of the $Q, R$, and $S$ deflections in the three standard leads ${ }^{1}$; the algebraic sum of the $T$ deflections in the three standard leads ${ }^{1}$; ( $R I$ or $2+S_{5}$ or 6 ) calculated as the sum of the highest $R$ in either $V_{I}$ or $V_{2}$, and the deepest $S$ in either $V_{5}$ or V6; ( $S r$ or $2+R_{5}$ or 6 ) calculated as the sum of the deepest $S$ in either VI or V2 and the highest $R$ in either $V_{5}$ or V6; $T$ amplitude in lead II; highest $T$ amplitude of the praecordial leads; and incomplete right bundle-branch block. In order to avoid inter-observer error all measurements were made by the same observer (L.V.).

The significance of the difference of the means was calculated by Student's $t$ test, except when there was a significant difference between the variances of the two groups ( $F$ test), in which case a non-parametric method (Mann-Whitney U test) was used. Correlation coefficients and $\chi^{2}$ were calculated by standard methods.

\section{Results}

Matching of groups The average age was 2 I.85 (I8.I to 29.9$) \pm 2.98$ years for the athletes and $21 \cdot 72(17.9$ to $30 \cdot 1) \pm 3 \cdot 10$ years for the controls. The difference between both groups is not significant $(t=0.32 \mathrm{I}, 0.7<\mathrm{p}$ $<0.8)$.

The average height of the athletes was 177.5 (I62 to 185$) \pm 5.8 \mathrm{~cm}$. Corresponding values for the controls were $177 \cdot 3$ (I67 to I85) $\pm 5 \cdot 1$ $\mathrm{cm}$. Again, the difference between both groups is not significant $(t=0.283,0.7<p<0.8)$.

The average weight of the athletes was $72 \cdot I$ $(6 \mathrm{I} \cdot 5$ to 84.5$) \pm 6 . \mathrm{I} \mathrm{kg}$., and the corresponding values for the control group $7 \mathrm{I} \cdot 8(60 \cdot 8$ to $86 \cdot 1)$

\footnotetext{
1 These quantities were chosen because, according to Simonson (196r), they follow a normal distribution in the general population.
}

TABLE I Matching of two groups

\begin{tabular}{llll}
\hline & Average age $(y r .)^{\star}$ & Average height $(\mathrm{cm} .)^{\star}$ & Average weight $(\mathrm{kg} .)^{\star}$ \\
\hline Athletes & $21 \cdot 85 \pm 2 \cdot 98$ & $177 \cdot 5 \pm 5 \cdot 8$ & $72 \cdot 1 \pm 6 \cdot 1$ \\
Controls & $21 \cdot 72 \pm 3 \cdot 10$ & $177 \cdot 3 \pm 5 \cdot 1$ & $71 \cdot 8 \pm 6 \cdot 5$ \\
\hline
\end{tabular}

^ Mean values \pm I SD.

$\pm 6.5 \mathrm{~kg}$. The difference between both groups

is not significant $(t=0.350,0.7<p<0.8)$.

These results are summarized in Table $I$.

\section{Electrocardiograph findings}

\section{Heart rate}

The average heart rate of the athletes was $53 \cdot 2 \pm 7 \cdot 4 / \mathrm{min}$. with extreme values of 44 and 75. The corresponding value for the controls was 70.8 (53 to 98$) \pm 10 \cdot 6 / \mathrm{min}$.

Since the variances of both groups differ significantly $(F=2.11 ; p<0.05)$, a MannWhitney test was used which showed a highly significant difference between the two groups $(z=5.06 ; p<0.001)$.

\section{$P Q$ interval}

Since no significant correlation was found between the PQ interval and the heart rate, in either the study group $(r=0.269 ; p>0.05)$ or the control group $(r=0.210 ; p>0.05)$, no correction was made for the heart rate. The average $P Q$ interval was $0.186 \mathrm{sec} . \pm 0.046 \mathrm{sec}$. in the athletes (range $0.120 \mathrm{sec} .-0.340 \mathrm{sec}$.) and $0.149 \mathrm{sec} \pm 0.027 \mathrm{sec}$. in the controls (range $0.100 \mathrm{sec} .-0.220 \mathrm{sec}$.). The variances of both groups differ significantly $(F=2.93$; $\mathrm{p}<0.01)$. The Mann-Whitney test is highly significant $(z=3.81 ; p<0.001)$.

\section{$Q R S$ interval}

The average in athletes was $0.098 \mathrm{sec}$. (range 0.060 sec. $-0.130 \mathrm{sec}$.) \pm 0.018 . The corresponding value for the control was $0.087 \mathrm{sec} . \pm$ $0.013 \mathrm{sec}$. (range $0.070 \mathrm{sec} .-0.120 \mathrm{sec}$.). The variances differ significantly $(\mathrm{F}=\mathbf{2} \cdot \mathbf{1 2} ; \mathrm{p}<$ $0.05)$. The Mann-Whitney test is significant at the 0.05 level $(z=2.00 ; p<0.05)$.

\section{$Q T c$ interval}

The average QT interval corrected for heart rate (QTc) in the athletes was 0.414 sec. \pm $0.032 \mathrm{sec}$. (range $0.35 \mathrm{sec} .0 .47 \mathrm{sec}$.).

The corresponding value in the controls was $0.366 \mathrm{sec} . \pm 0.020 \mathrm{sec}$. (range $0.340 \mathrm{sec}$. $0.410 \mathrm{sec}$.). The variances are significantly different $(F=2.76 ; p<0.05)$. The MannWhitney test is highly significant $(z=4.31$; $\mathrm{p}<0.001$ ). 
QRS axis

The average QRS axis in athletes was $+6 \mathrm{I} \cdot 2^{\circ}$ $\pm 35.7^{\circ}$ (range $\left.-50^{\circ}-+103^{\circ}\right)$. The corresponding value in the controls was $+55.0^{\circ} \pm 38.8^{\circ}$ (range $\left.-62^{\circ}-+100^{\circ}\right)$. No significant difference was found between both groups $(t=0.91$; $\mathrm{p}>0.2$ ).

$T$ axis

The average $T$ axis in athletes was $+39.3^{\circ}$ $\pm 23.8^{\circ}$ (range $-35^{\circ}-+81^{\circ}$ ). The corresponding value in controls was $+50.0^{\circ}$ (range $\left.-5^{\circ}-+122^{\circ}\right) \pm 19 \cdot 8^{\circ}$. The difference between the two groups is significant $(t=2 \cdot 70$; $\mathrm{p}<0.0 \mathrm{I}$ ).

Algebraic sum of $Q, R$, and $S$ deflections in three standard leads

The average value of the algebraic sum of the $\mathbf{Q}, \mathbf{R}$, and $\mathbf{S}$ deflections in the three standard leads was $20.94 \pm 13.28 \mathrm{~mm}$. in athletes (range $-2.75-48.50$ ) and $19.00 \pm 10.67 \mathrm{~mm}$. in controls (range $-0.75-38 \cdot 50)$. The difference between the two groups is not significant $(t=0.89 ; p<0.2)$.

Algebraic sum of $T$ deflections in three standard leads

The average value of the algebraic sum of the $T$ deflections in the three standard leads was $8.18 \pm 3.82 \mathrm{~mm}$. (range $-1.00-14.75$ ) in athletes and $6.70 \pm 2.58 \mathrm{~mm}$. (range $\mathrm{I} \cdot 50$ and 12.75) in controls. The variances of both groups are significantly different $(F=2 \cdot 18$; $\mathbf{p}<0.05)$. The Mann-Whitney test shows no significant difference between the two groups $(z=1 \cdot 74 ; p>0.05)$.

\section{$T$ amplitude in lead II}

The average amplitude of the $T$ wave in lead II was 3.98 (range $-0.50-7.00$ ) $\pm \mathrm{x} .86 \mathrm{~mm}$. in athletes and 3.28 (range $0.50-6.00$ ) $\pm \mathrm{r} .22$ $\mathrm{mm}$. in controls. The variances are signifi- cantly different $(F=2.30 ; p<0.05)$. The difference between both groups is significant at the 0.05 level (Mann-Whitney's $z=2.08$; $\mathrm{p}<0.05)$.

Sum of the deepest $S$ in either $V_{I}$ or 2 and highest $R$ in either $V 5$ or V6

The average value of this sum was 39.56 (range $19.00-69.50) \pm 10.14 \mathrm{~mm}$. in athletes and 33.15 (range $13.25-57.50$ ) $\pm 9.69 \mathrm{~mm}$. in controls. The difference between both groups is highly significant $(t=3.54 ; p<0.001)$.

Sum of the highest $R$ in either $V_{I}$ or $V_{2}$ and deepest $S$ in either $V 5$ or V6

The average value of this sum was 12.08 $\pm 5.72 \mathrm{~mm}$. in athletes (range $3.25-22.25$ ) and $9.93 \pm 5.63 \mathrm{~mm}$. in controls (range $3.00-$ 26.50). The difference between both groups is significant $(t=2.09 ; p<0.05)$.

Maximal $T$ amplitude in praecordial leads

The average value of the highest $T$ waves in the praecordial leads was 8.33 (range 3.25 13.00) $\pm 2.68 \mathrm{~mm}$. in athletes. The corresponding value in controls was 8.55 (range $2.00-$ 14.00) $\pm 2.75 \mathrm{~mm}$. The difference between both groups is not significant $(t=0.45$; $\mathrm{p}>0.2)$.

\section{Other results}

(I) Right bundle-branch block (either 'incomplete' or 'physiological' as described in athletes by Slapak (1957)) was present in 8 athletes and in 6 controls. The difference in prevalence between both groups is not significant. $\left(\chi^{2}=0.13 ; p>0.05\right)$.

(2) One athlete had negative $T$ waves in leads II, III, and $\mathrm{aVF}$, and biphasic $\mathrm{T}$ waves in $V_{5}$ and V6. Another had multiple unifocal ventricular extrasystoles. Subsequent clinical examinations did not show any pathological condition responsible for these findings, and

TABLE 2 Electrocardiograph findings

\begin{tabular}{|c|c|c|c|c|}
\hline & Athletes* & Controls* & Significance & \\
\hline $\begin{array}{l}\text { Heart rate } \\
\text { QRS axis } \\
T \text { axis } \\
\text { PQ interval in lead II } \\
\text { QRS interval } \\
\text { QTc interval } \\
\text { Agebraic sum of } Q, R \text {, and } S \\
\text { Algebraic sum of } T \text { waves } \\
\left(\mathbf{R I} \text { or } 2+S_{5} \text { or } 6\right) \\
(S I \text { or } 2+R 5 \text { or } 6) \\
T \text { amplitude in lead II } \\
\text { T maximum praecordial leads } \\
\text { Incomplete right bundle-branch } \\
\text { block }\end{array}$ & $\begin{array}{c}53 \cdot 2 \pm 7 \cdot 4 \\
+61 \cdot 2 \pm 35 \cdot 7^{\circ} \\
+39 \cdot 3 \pm 23.8 \\
0.186 \pm 0.046^{\prime \prime} \\
0.098 \pm 0.018^{\prime \prime} \\
0.414 \pm 0.032^{\prime \prime} \\
20.94 \pm 13.28 \\
8.18 \pm 3 \cdot 82 \\
12.08 \pm 5 \cdot 72 \\
39.56 \pm 10.14 \\
3.98 \pm 1.86 \\
8.33 \pm 2.68 \\
8\end{array}$ & $\begin{array}{c}70.8 \pm 10.6 \\
+55.0 \pm 38.8^{\circ} \\
+50.0 \pm 19.8^{\circ} \\
0.149 \pm 0.027^{\prime \prime} \\
0.087 \pm 0.013^{\prime \prime} \\
0.366 \pm 0.020^{\prime \prime} \\
19.00 \pm 10.67 \\
6.70 \pm 2.58 \\
9.93 \pm 5.63 \\
33.15 \pm 9.69 \\
3.28 \pm 1.22 \\
8.55 \pm 2.75 \\
6\end{array}$ & $\begin{array}{l}p<0.001 \\
\text { Not significant } \\
p<0.01 \\
p<0.001 \\
p<0.05 \\
p<0.001 \\
\text { Not significant } \\
\text { Not significant } \\
p<0.05 \\
p<0.001 \\
p<0.05 \\
\text { Not significant } \\
\text { Not significant }\end{array}$ & \\
\hline
\end{tabular}

* Mean values \pm I SD. 
an exercise test was normal. Furthermore, their results in competitive sport were quite good. No such anomalies were encountered in the controls. Benign arrhythmias, for example sinus arrhythmia, were encountered equally in both groups and are not dealt with in this study. The electrocardiographic findings are summarized in Table 2 which shows the average values and the standard deviations of the measurements and the significance of the differences between both groups.

\section{Discussion}

Since the first description of the electrocardiogram in athletes (Hoogerwerf, 1929), many reports have been published on the subject. Comprehensive reviews have been written by Reindell et al. (1960) and by Butschenko (1967). Most authors agree that the following findings are particularly common: sinus bradycardia, incomplete right bundle-branch block, right QRS axis shift, left T axis shift, high amplitude of the $P$ waves in lead II, prolonged $P Q$ and $Q R S$ intervals, increased sum of the highest $R$ waves and the deepest $S$ waves in the praecordial leads, high $T$ waves in lead II, ST depression or elevation, and high $T$ waves in the praecordial leads. Less common features are $U$ waves, Wenckebach heart block, and changes in the shape of the $\mathbf{P}$ waves, for example biphasic or notched. Some of these features might be attributable to factors unrelated to the state of physical training, such as age, sex, and height. Furthermore, some apparently abnormal electrocardiograms are also encountered in a noteworthy percentage of the general population. For instance, in the largest single series of a healthy male population, Hiss and Lamb (1962) found first-degree AV block in 7.4 per IO00 in the age-group 20-24. Thus, the normal range of electrocardiographic variations is larger than at one time assumed, and this makes it inadvisable to try to assess the significance of any peculiar features in a particular group without reference to suitable controls.

Interesting negative findings of this study, therefore, are the absence of significant differences in QRS axis (despite high praecordial $Q R S$ voltages suggestive of ventricular hypertrophy in athletes), in the amplitude of the T waves in the praecordial leads, and in the prevalence of incomplete right bundle-branch block.

The choice of the sum of $S_{1}$ or $2+R_{5}$ or 6 and $R_{1}$ or $2+S_{5}$ or 6 to assess possible ventricular hypertrophy may appear arbitrary. The sum of the mean greatest $R+$ greatest $S$ in the praecordial leads has been used by Kilty and Lepeschkin (1965) who pointed out that the QRS voltage was greatly influenced by body build. This may be the explanation for the clinical and necropsy finding (Grubschmidt and Sokolow, 1957) that high QRS voltages may be present in adolescents and adults under the age of 25 in the absence of left ventricular hypertrophy.

In a critical study of several criteria for left ventricular hypertrophy in a group of healthy males comparable in age to ours, Manning and Smiley (1964) found a value of $53 \mathrm{~mm}$. for the 99th percentile of the sum of the maximal $R$ in $\mathrm{V}_{5}$ or $\mathrm{V} 6+\mathrm{S}$ in VI. This agrees closely with our data, since we found only I control subject out of 30 who exceeded this value. It is of interest that only one athlete also exceeded this limit. It thus appears that the whole distribution of this parameter is shifted around a higher average value in athletes.

With regard to right ventricular hypertrophy, a criterion similar to ours, namely the sum of $R$ in VI and the deepest $S$ in $V_{5}$ or V6, was first described by Sokolow and Lyon (1949) and applied to the study of athletes by Arstila and Koivikko (I966). They found it to be well correlated with vectorcardiographic but not with radiographic indices of right ventricular hypertrophy. They also found that right ventricular dominance was relatively more common in younger athletes (similar to our group) than in older ones, for example Marathon runners. However, criteria correctable for age, comparable to those of Manning and Smiley (1964) for left ventricular hypertrophy, have not been described yet for right ventricular hypertrophy, a point that may deserve further study. We did not find any association, either in athletes or controls, between incomplete right bundle-branch block and right ventricular hypertrophy as defined above.

The other results, as in previous investigations on athletes, differ significantly from the findings in the non-trained group. What significance is to be ascribed to such findings ?

The most prevalent view is that a causal relation exists between the training status and the electrocardiographic findings. For example, Cullen and Collin (1964) reported the appearance of cardiac arrhythmias after a period of daily running in two healthy subjects with previously normal electrocardiograms. Yet, it is not clear whether the basis for these changes are morphological alterations such as ventricular hypertrophy - in rare cases confirmed at necropsy (Kirch, 1935) - or functional changes (embodied in the vague entity of vagotonia), which may dis- 
appear after atropine (Prokop and Slapak, 1958) or even during physical exercise.

Other explanations are possible. First, athletes differ from non-trained individuals not only with regard to their training status but also in their intrinsic (genetic) ability to sustain exhausting physical effort. They differ also in their general mode of life, for example, diet, rest, and smoking. Thus, individuals involved in competitive sport have been subjected to a selection, which is based partly on genetic and partly on environmental factors. Some of the latter, for example glucose ingestion (athletes often adhere to a diet rich in carbohydrate), are well known to cause acute electrocardiographic changes (Ostrander and Weinstein, 1964). Second, it may well be that physical training induces changes in the heart muscle which are not related to the physical fitness and which may even be harmful in some subjects. This hypothesis is consistent with the repeatedly reported finding that second-rate athletes exhibit electrocardiographic changes approximately as often as topclass ones (von Csinády, 1930; Klemola, 1951 ; Karvonen, 1959; Smith, Cullen, and Thorburn, 1964; Häntzschel and Dohrn, 1966). It could also explain our previous finding that no correlation exists between the electrocardiographic findings and the physical fitness as measured by the oxygen uptake during submaximal exercise (Van Ganse and Versee, 1968).

We believe that the only means of investigating the significance of these electrocardiographic findings are prolonged prospective studies of athletes from the very start of their careers. Such studies will necessitate comparison with untrained controls, since more often than not competitive sport is started in adolescence when full physical development has not yet been achieved.

The authors acknowledge the help of Dr. R. Marlier who referred most of the athletes to us, and the Belgische Wielrijders Bond for permission to study their records.

\section{References}

American Heart Association, Committee on Electrocardiography (1954). Report. Recommendations for Standardization of Electrocardiographic and Vectorcardiographic leads. Circulation, 10, 564.

Arstila, M., and Koivikko, A. (1966). Electrocardiographic and vectorcardiographic signs of left and right ventricular hypertrophy in endurance athletes. Fournal of Sports Medicine and Physical Fitness, 6, 166.

Beckner, G. L., and Winsor, T. (1954). Cardiovascular adaptations to prolonged physical effort. Circulation, 9,835 .
Blackburn, H. (1965). The electrocardiogram in cardiovascular epidemiology: Problems in standardized application. Annals of the New York Academy of Sciences, 126, 882.

Butschenko, L. A. (1967). Das Ruhe-und BelastungsEKG bei Sportlern. Johann Ambrosius Barth, Leipzig.

von Csinády, E. (1930). Sportärztliche Untersuchungen. III. Mitteilung: Vergleichende elektrokardiographische Untersuchungen an Sporttreibenden, bei besonderer Berücksichtigung der 'EKG' Zeitwerte. Arbeitsphysiologie, 3, 579.

Cullen, K. J., and Collin, R. (1964). Daily running causing Wenckebach heart-block. Lancet, 2, 729.

Grubschmidt, H. A., and Sokolow, M. (1957). The reliability of high voltage of the QRS complex as a diagnostic sign of left ventricular hypertrophy in adults. American Heart fournal, 54, 689.

Häntzschel, K., and Dohrn, K. (1966). The electrocardiogram before and after a Marathon-race. fournal of Sports Medicine and Physical Fitness, 6, 28.

Hiss, R. G., and Lamb, L. E. (1962). Electrocardiographic findings in 122,043 individuals. Circulation, 25,947 .

Hoogerwerf, S. (1929). Elektrokardiographische Untersuchungen der Amsterdammer Olympiakämpfer. Julius Springer, Berlin.

Karvonen, M. J. (1959). Effects of vigorous exercise on the heart. In Work and the Heart: Trans. Ist Wisconsin Conference on Work and the Heart, p. 199. Ed. by F. F. Rosenbaum and E. L. Belknap. Hoeber, New York.

Kilty, S. E., and Lepeschkin, E. (1965). Effect of body build on the QRS voltage of the electrocardiogram in normal men. Circulation, 31, 77.

Kirch, E. (1935). Anatomische Grundlagen des Sportherzens. Verhandlungen der deutschen Gesellschaft für innere Medizin, 47, 73.

Klemola, E. (195I). Electrocardiographic observations on 650 Finnish athletes. Annales Medicinae Internal Fenniae, 40, 121.

Manning, G. W., and Smiley, J. R. (1964). QRSvoltage criteria for left ventricular hypertrophy in a normal male population. Circulation, 29, 224.

Ostrander, L. D., and Weinstein, B. J. (1964). Electrocardiographic changes after glucose ingestion. Circulation, 30, 67.

Prokop, L., and Slapak, L. (1958). Sport und Kreislauf. Maudrich, Vienna.

Reindell, H., Klepzig, H., Steim, H., Musshoff, K., Roskamm, H., and Schildge, E. (1960). Herz, Kreislaufkrankheiten und Sport. Johan Ambrosius Barth, Munich.

Simonson, E. (196r). Differentiation between Normal and Abnormal in Electrocardiography. C. V. Mosby, St. Louis.

Slapak, L. (1957). Zum Ekg-Bild des unvollständigen Rechtsschenkelblocks. Zeitschrift für Kreislaufforschung, 46, 373.

Smith, W. G., Cullen, K. J., and Thorburn, I. O. (1964). Electrocardiograms of marathon runners in 1962 Commonwealth Games. British Heart fournal, 26, 469 .

Sokolow, M., and Lyon, T. P. (1949). The ventricular complex in right ventricular hypertrophy as obtained by unipolar precordial and limb leads. American Heart fournal, 38, 273.

Van Ganse, W., and Versee, L. (1968). The electrocardiogram in athletes: a controlled study. Atti $V^{e}$ Congresso Internationale di Igene $e$ Medicina Preventiva, Roma, 8-12 October 1968, Vol. 2, p. 293. 